\title{
Developmental Modulations of Blood-Brain Barrier Permeability as an Indicator of Changing Nutritional Requirements in the Brain
}

\author{
EAIN M. CORNFORD, ${ }^{(39)}$ LEON D. BRAUN, AND WILLIAM H. OLDENDORF \\ Southwestern Regional V.A. Epilepsy Center, Veterans Administration Medical Center, Wadsworth; Research Service, \\ Veterans Administration Medical Center, Brentwood, Los Angeles, California, and Department of Neurology, Reed \\ Neurological Research Center, UCLA School of Medicine, Los Angeles, California, USA
}

\begin{abstract}
Summary
The intracarotid injection technique has been utilized to examine blood-brain barrier function in studies of newborn $(>24 \mathrm{~h}), 7$, 14, 21 and 28 day-old, as well as adult rabbits. The age-related modulations in blood-brain barrier transport of adenine, arginine, choline, lactate and tryptophan were defined and demonstrated to be independent of each other. Lactic acid uptake was unusual in that the brain uptake index (BUI) was found to be greatest at 7 days postpartum. Elevated lactate uptake continues until 14 days and is then reduced. As indicated below, for all of the other metabolites examined, a maximal BUI was observed in the newborn brain and BUIs typically showed some sort of inverse relationship to animal age. The BUI of arginine is apparently halved in the first 7 days postnatally, and continues to decrease, reaching the value seen for the adult rabbit by an age of 21 days. In contrast, the brain uptake of adenine is unusual in that there appears to be a very gradual reduction in brain uptake occurring throughout the suckling period. A 3-fold decrease in the BUI of choline was observed during the first 2 wk postpartum. Tryptophan uptake undergoes a 4-fold reduction in the first 4 wk postnatally. Only minor variations in the uptakes of glucose and butanol (a reference substance which is completely cleared by brain over a wide range of blood flow rates) were observed over the range of ages examined. Therefore modulations in adenine, arginine, choline, lactate and tryptophan permeability are not attributable to blood flow alterations.
\end{abstract}

\section{Speculation}

The brain uptake rates of the metabolites which gain access by way of specific carrier mediated transport mechanisms are presumed to reflect nutritional requirements of the developing brain. Thus the present study indicates that the inclusion of these metabolites (adenine, arginine, choline, tryptophan and monocarboxylic acids such as lactate) would be beneficial in clinical intravenous feeding of the neonate, to meet the apparent needs of the developing central nervous system.

Age related changes in brain amino acid uptake have been described in both rats (34) and chickens (31). Differences have also been suggested in studies of choline (8) as well as glucose and monocarboxylic acid (10) uptake by the developing rat brain. Other recent studies also confirm age related changes in glucose uptake in rat brains and attribute the changes to a shift from the use of ketone bodies as a brain energy source in the weanling, to glucose in the adult. $(12,21)$. The demonstration of a sophisticated, selectively permeable blood-brain barrier (BBB) in newborn rabbits has been described recently (4). Furthermore, this barrier prevents the entry of sucrose (30), mannitol, dextran an indium- bound EDTA (4). These studies emphasize that the restrictive properties of newborn brain endothelia are as exclusive as those seen in the mature adult brain.

Saunders (33) has noted that early studies on the penetration of dyes into brain have frequently been misquoted as suggesting that the $\mathrm{BBB}$ in newborn animals is freely permeable. Although some misconceptions still persist, this spurious suggestion of an immature or incomplete BBB in the neonate has been laid to rest in the light of overwhelming evidence to the contrary (33). The exclusion of protein-bound (but not free) bilirubin by newborn brain capillaries $(13,14,19)$ has also emphasized the clinical relevence of investigations of the developing BBB.

In the present study we have assumed that uptake rates reflect the nutritional needs of the brain. Thus, comparisons of newborn, suckling and adult brains provide an indication of the changing nutritional requirements of the brain. Studies of rabbits at various ages (newborn, 7, 14, 21, 28 days and adults) were performed to compare brain uptake of substrates representing five of the major $\mathrm{BBB}$ carrier transport systems (adenine, arginine, choline, lactate and tryptophan), as well as butanol. [Butyl alcohol is a commonly used reference substance because it is completely cleared by brain in a single transcapillary transit, over a wide range of blood flows (32). Substances that are not transported by selective carrier systems gain entry into brain by virtue of their lipophilic properties (23)]. Data are presented which suggest that the newborn brain possesses mechanisms to ensure a supply of these metabolites (pariticularly neurotransmitter precursors) to brain, and their possible relevence to neonatal medicine is discussed.

\section{MATERIALS AND METHODS}

Animal Methods. New Zealand white rabbits were obtained from a commercial supplier; adults were maintained on a standard diet of water and rabbit chow. All animal studies were performed in the early afternoon. Although newborn rabbits were obtained as soon as possible postpartum, in most instances they were a minimum of $10 \mathrm{~h}$ old and routinely had maternal milk intubated into the stomach. The common carotid artery was surgically exposed under ether anesthesia and cannulated with a $30 \mathrm{G}(0.3$ $\mathrm{mm})$ needle. The intracarotid injection technique $(22,24,25)$ was modified slightly for study of newborn and adult rabbits. An intraarterial bolus injection $(0.10 \mathrm{ml})$ containing tritiated water as a diffusible reference, a $\left[{ }^{14} \mathrm{C}\right]$ test substance, and an internal diffusible reference consisting of $\left[{ }^{113 \mathrm{~m}} \mathrm{In}\right.$ ]-EDTA was performed. The mixture of isotopes injected was routinely buffered with 10 mM HEPES (Calbiochem, La Jolla, CA). The rabbit was decapitated $10 \mathrm{sec}$ after injection. The brain was removed and the hemisphere ipsilateral to the carotid injection was sampled and prepared for simultaneous $\left[{ }^{3} \mathrm{H}\right],\left[{ }^{14} \mathrm{C}\right]$, and $\left[{ }^{113 m} \mathrm{In}\right]$ counting.

In studies of 28-day-old rabbits, a $0.2 \mathrm{ml}$ volume was injected. In adult rabbits (approximately $2 \mathrm{~kg}$ ), the method differed in that 
the anesthetic, sodium pentobarbital (Diabutal, Diamond Laboratories, at a dose of about $40 \mathrm{mg} / \mathrm{kg}$ ), was administered $\mathrm{IV}$, and a larger needle $(22 \mathrm{G})$ and injection volume $(1.0 \mathrm{ml})$ were used. Adults were decapitated $10 \mathrm{sec}$ after injection. Because of the larger brain size, regions of the ipsilateral forebrain were routinely prepared for scintillation counting and analysis of brain uptake as described previously (9). Brain uptake of a $\left[{ }^{14} \mathrm{C}\right]$ labeled test substance is expressed relative to the uptake of tritiated water $\left[{ }^{3} \mathrm{H}\right]$ water, and the third isotope, $\left[{ }^{113 \mathrm{~m}} \mathrm{In}\right]$ (bound to EDTA) serves as a vascular space marker identifying that portion of the isotopes remaining in the vasculature (26). Subtraction of this amount provides an estimate of the amount incorporated by brain, termed the brain uptake index (BUI). The ipsilateral forebrain was dissected out, the tissue digested with an organic base (Soluene, Packard Instruments), and routinely counted without delay in a liquid scintillation counter for Indium content. Days later, after all of the $\left[{ }^{113 \mathrm{~m}} \mathrm{In}\right]\left(t^{1 / 2}=100 \mathrm{~min}\right)$ had decayed, the vials were recounted for $\left[{ }^{3} \mathrm{H}\right]$ and $\left[{ }^{14} \mathrm{C}\right]$ content.

Data Analysis. The net Indium counts are obtained by subtraction and appropriate decay correction (when vials are sequentially counted for Indium disintegrations in $1 \mathrm{~min}$, each successive vial must be decay-corrected for the elapsed counting time i.e., $1.0 \mathrm{~min}$ plus the time required by the machine to change samples, i.e., 0.3 min). Counts per min (cpm) recorded on the liquid scintillation counter are converted to distintegrations per min (dpm) by cubic regression analysis on a Hewlett-Packard 9820 programmable calculator.

BUIs are determined as defined by Oldendorf and Braun (26) from the ratio:

$\mathrm{BUI} /(100 \%)$

$$
=\left[\frac{\frac{\left[{ }^{14} \mathrm{C}\right] \text { test substance }}{\left[{ }^{3} \mathrm{H}\right] \text { water }} \text { (brain) }}{\frac{\left[{ }^{14} \mathrm{C}\right] \text { test substance }}{[\text { in mix })}}-\frac{\frac{\left[{ }^{13 \mathrm{~m}} \mathrm{In}\right] \text {-EDTA }}{\left[{ }^{3} \mathrm{H}\right] \text { water }} \text { (brain) }}{\frac{\left[{ }^{13 \mathrm{~m}} \mathrm{In}\right] \text {-EDTA }}{\left.{ }^{3} \mathrm{H}\right] \text { water }} \text { (in mix) }}\right]
$$

(where "mix" = the isotope mixture injected into the carotid artery). The Indium(-EDTA) uptake index (=IUI) is defined as the subtrahend of the BUI ratio described above.

Unless otherwise indicated, all values are presented in the form of a mean $(=\bar{X})$, standard deviation (=S.D.) and sample number $(=n)$. The students $t$ test was employed as an indicator of statistically significant means.

Radiochemicals. All of the radiochemicals $\left[{ }^{14} \mathrm{C}\right]$ arginine, adenine, choline, glucose, lactate, tryptophan, butanol, lysophosphatidyl choline and tritiated water were purchased from New England Nuclear Corporation, Boston, MA, and were of the highest specific activity available. Defatted bovine serum albumin (Sigma Chemical Company, St. Louis, MO) was added at a concentration of $0.1 \%$ to effect solubility of the lysolecithin. The [ $\left.{ }^{113 \mathrm{~m}} \mathrm{In}\right]$ generator was supplied by NEN radiopharmaceutical division, North Bilerica, MA. The radioisotopic purity of each $\left[{ }^{14} \mathrm{C}\right]$ test isotope was routinely confirmed after thin layer chromatographic separation on silica gel plates using a solvent system recommended by the manufacturer. Dried plates were scanned using a Berthold Varian radiochromatogram scanner.

\section{RESULTS}

Lactic acid uptake is unusual in that the BUI was found to be greatest at 7 days postpartum. Elevated lactate uptake continues until 14 days and then undergoes a 6-fold reduction (Fig. 1). As indicated below, for all of the other metabolites examined, a maximal BUI was observed in the newborn brain and BUIs typically showed some sort of inverse relationship to animal age.

The BUI of arginine is apparently halved in the first 7 postnatally, and continues to decrease, reaching the value seen for the adult at an age of 21 days (Fig. 2). These data indicate an 8-fold difference in brain uptake of this basic amino acid occurs in the first 3 wk of life.

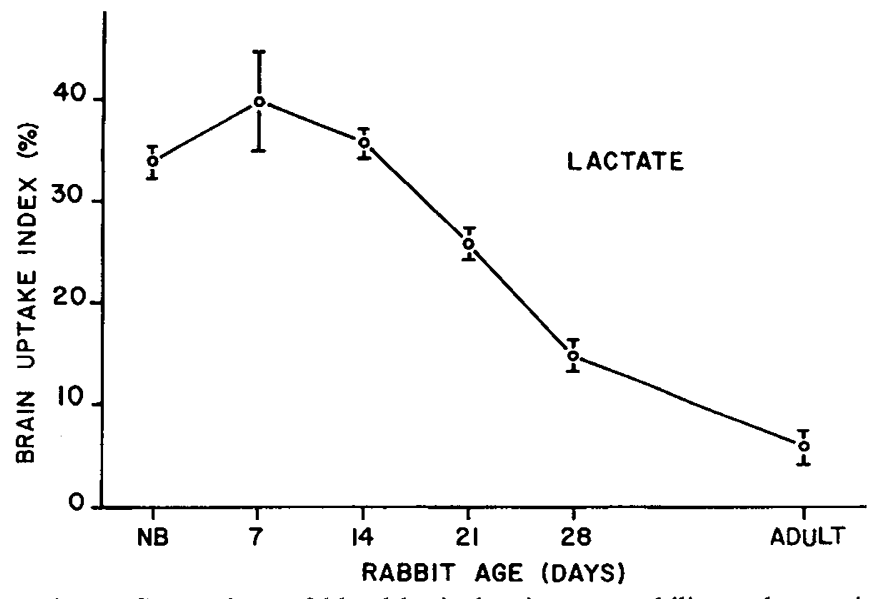

Fig. 1. Comparison of blood-brain barrier permeability to lactate in newborn, 7, 14, 21, 28-day-old and adult rabbits studied after intracarotid injection. The injected concentration was $7 \mu \mathrm{M}$. Values listed are mean BUIs derived from a sample size of 3-7. Vertical bars represent S.D. NB = Newborn.

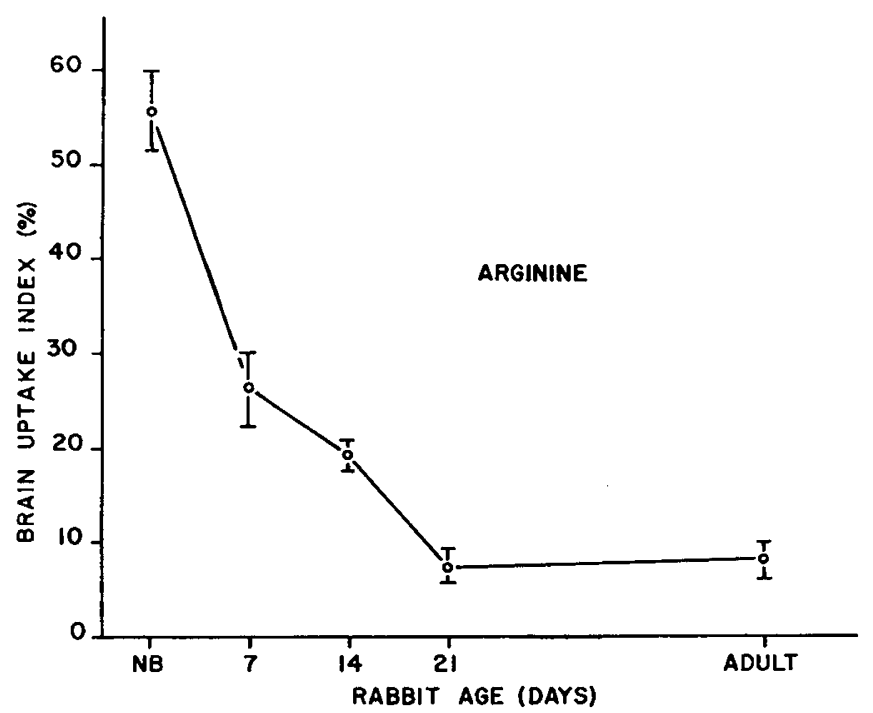

Fig. 2. Age-related modulation in blood-brain barrier transport of 8 $\mu \mathrm{M}$ arginine in the rabbit. Mean BUIs ( \pm S.D.) are depicted, $n=3-6$.

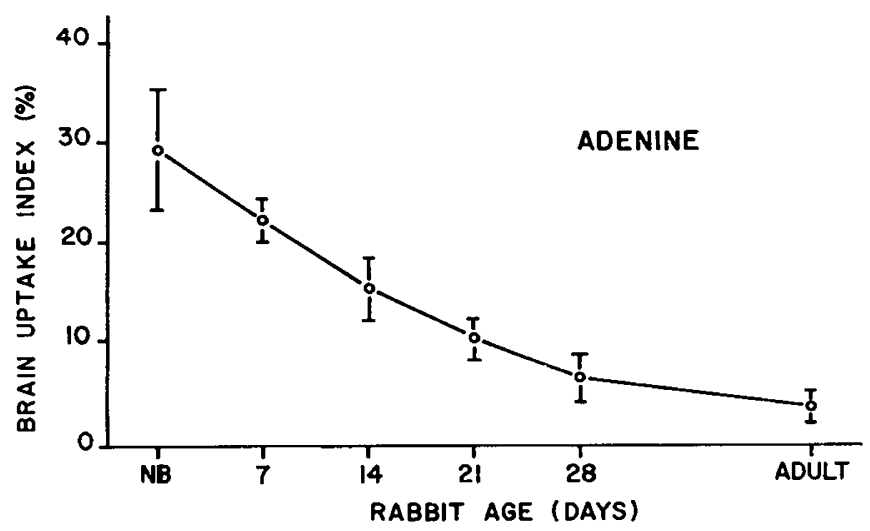

Fig. 3. Age-dependent modulation in blood-brain barrier transport of the purine base adenine $(35 \mu \mathrm{M})$. Mean BUIs ( \pm S.D.) are depicted, $n=$ $3-6$.

In contrast, the brain uptake of adenine (Fig. 3) is unusual in that there appears to be a very gradual reduction in brain uptake occurring throughout the suckling period (our supplier indicates that rabbits are typically weaned at about 35 days old). In previous 
studies, the absence of transport of pyrimidine bases was reported (6) in the adult BBB. Studies of cytosine uptake indicate a BUI $=1.2 \pm 0.5 \%$ for this pyrimidine nucleoside in the newborn rabbit, and further emphasize the specific selectivity of the newborn BBB.

Choline transport in the developing brain was of great interest because choline is a precursor of both phosphatidyl choline (lecithin, a component of cell membranes) and the neurotransmitter acetylcholine. A 3-fold decrease in the BUI of choline was observed during the first 2 wk postpartum (Fig. 4). Apparently there is little change in brain choline uptake during the latter suckling period, and only a very minor increase in BUI is associated with the transition to solid food. Since lysolecithin is a dietary source of choline (18) we also compared its brain uptake in newborn $(\mathrm{BUI}=5.7 \pm 1.4 \%)$ and adult $(\mathrm{BUI}=3.2 \pm 2.3 \%$ ) brains. The failure of lysolecithin to penetrate the $\mathrm{BBB}$ suggests that brain lecithins are probably synthesized from plasma choline, or that they have a long biologic half-life in the brain.

Tryptophan uptake undergoes a 4-fold reduction in the first 4 wk postnatally but then increases such that the adult BUI is less than half that seen in the newborn brain (Fig. 5). In the presence of $0.5 \%$ defatted bovine serum albumin, the BUI in newborns (51 $\pm 7 \%$ ) was not significantly different from that observed in the presence of saline $(56 \pm 5 \%)$. This confirms the observation that

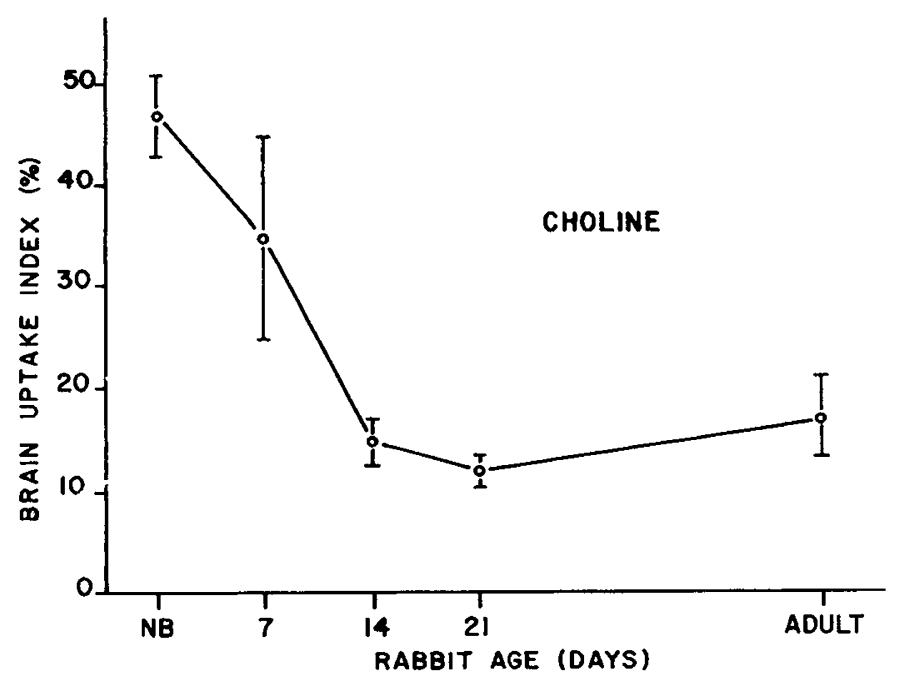

Fig. 4. Age-dependent modulation in blood-brain barrier transport of choline (45 $\mu \mathrm{M})$. Mean BUIs ( \pm S.D.) are depicted, $n=3-6$.

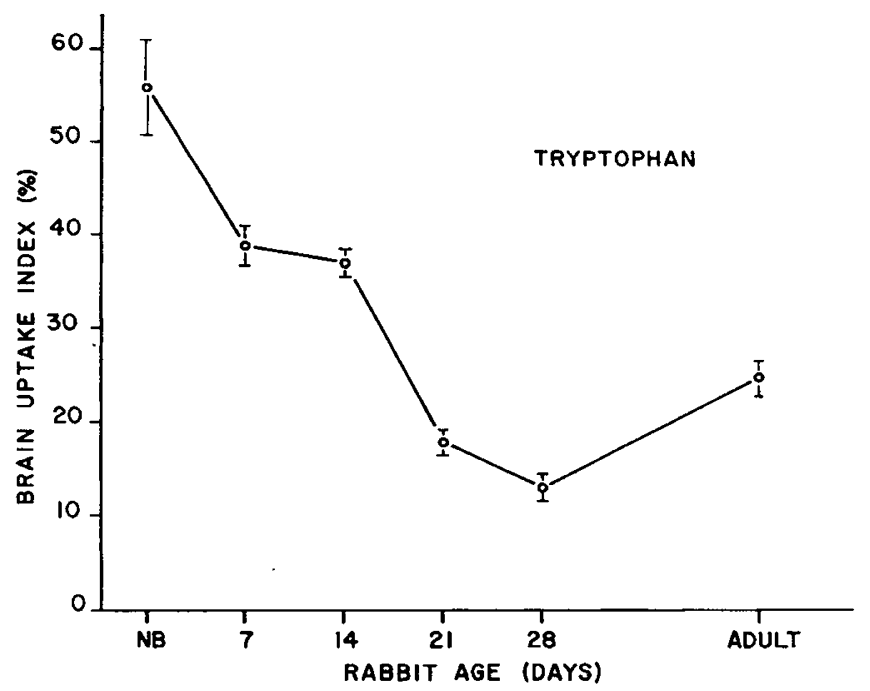

Fig. 5. Age-dependent modulation in blood-brain barrier transport of tryptophan $(20 \mu \mathrm{M})$. Mean BUIs ( \pm S.D.) are depicted, $n=3-6$.

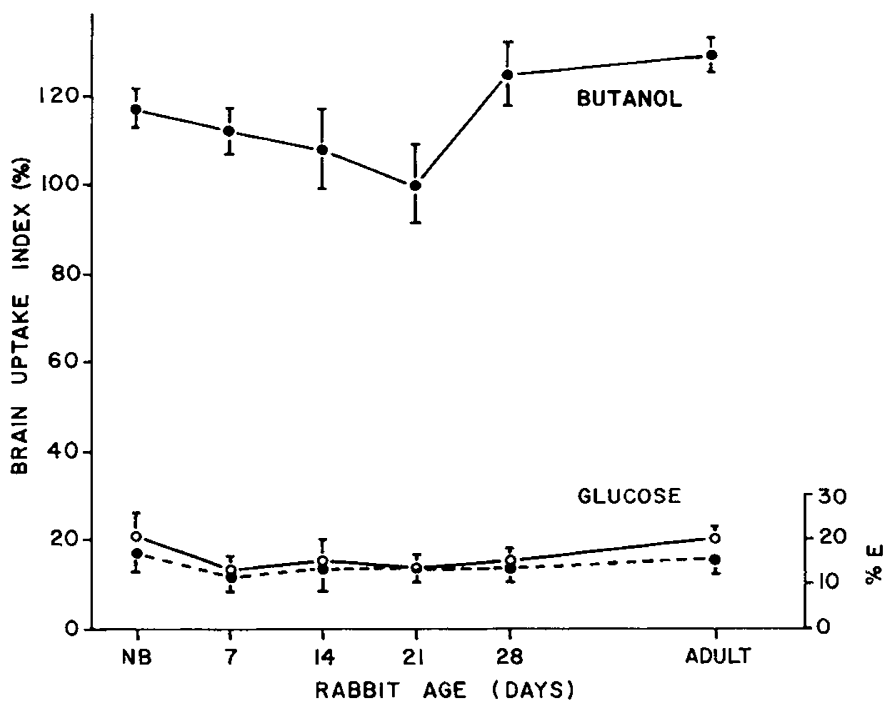

Fig. 6. Age-dependent alteration in blood-brain barrier permeability to glucose and butanol, a substance that is completely cleared in a single transcapillary transit over a wide range of blood flow rates. The BUIs depicted are means, vertical bars represent 1 S.D., $n=3-6$. Glucose BUI is represented by the solid line. The broken line represents glucose extraction (E\%), determined by dividing the BUI(glucose) by the BUI(butanol), and normalizes for possible age-related blood flow differences.

bound tryptophan gains access to the neonatal brain (20) just as has been demonstrated in the adult rat $\operatorname{BBB}(28,36)$.

Butanol uptake (measured relative to the diffusion of water) was not constant throughout the range of ages examined (Fig. 6), but marked differences were not observed. In contrast, the brain uptake of glucose is quite uniform throughout the range of ages examined (Fig. 6). Although age-dependent variations in butanol uptake suggest slight changes in cerebral blood flow, the magnitude of change in adenine, arginine, choline, lactate and tryptophan permeabilities are too great to be explained on the basis of alterations in cerebral blood flow rates. Indium-EDTA Uptake Indices, measured in newborn $(7.4 \pm 3.5 \%)$, 7 -day $(3.8 \pm 1.2 \%)$, 14 -day $(1.5 \pm 0.4 \%)$, 21-day $(1.5 \pm 0.5 \%)$, 28-day $(1.1 \pm 0.3 \%)$ and adult $(1.2 \pm 0.9 \%)$ rabbits also indicate that the cerebrovascular system is in a state of flux during these developmental periods.

\section{DISCUSSION}

The selective exclusion of metabolites such as lysolecithin and cytosine confirms previous suggestions $(4,30,33)$ that the concept of an "immature" barrier at birth seems untenable and inconsistent with current understanding of the BBB. Furthermore, the agerelated changes observed for brain IUI suggest that there may be an alteration in the cerebral vasculature as well as blood flow occurring soon after birth. The concept of "capillary intermittency," i.e., the stretching of endothelial cells and/or the opening up of new capillaries is a well accepted phenomenon in muscle tissue. Bolwig et al. $(2,3)$ have proposed that this phenomenon occurs during seizure in the brain, but this seems to be an unresolved issue (7). The opening of new capillaries (i.e., "developmental patency," rather than "capillary intermittency") seems to best explain the present observations. Electron microscopic studies of rat brain capillaries suggest that there is an increase in the \% of patent capillaries during the period 10-20 days postpartum (5). If the closed capillaries function like a series of blind diverticuli before becoming patent, the alterations in IUI observed in the present study can be considered to be consistent with the functional opening of additional capillary channels. Under such conditions, the concept of developmental patency could be supported by both morphologic and in vivo studies. It is also possible that a small proportion of the capillaries of the neonatal brain 
may be functionally characterized as having a greatly increased transit time, and the transit times of this group of capillaries would increase to normal rates during development. Decreases in the IUI would also be consistent with large scale decreases in capillary transit time.

The dramatic alterations in brain uptakes of adenine, arginine, choline, lactate and tryptophan seem best explained by induction of the transport mechanisms, which have been demonstrated in newborn capillaries (4). Although variability in butanol uptakes is indicative of minor age-related alterations in cerebral blood flow, a recent comparative study of infant and adult rats indicates that the lower infant flow rates are not signicantly different from rates observed in the adult (11).

Previous studies have established that elevated brain uptake of monocarboxylic acids such as lactate can be correlated with the use of ketone bodies as an energy source in the neonate. As the shift to glucose occurs with age, there is a drop in brain uptake of monocarboxylic acids $(10,12,21)$. Adenine is an important nucleic acid precursor, and adenyl compounds are important with respect to high energy phosphate bonds, so the developing brain presumably has an increased need for this purine. Since choline is probably not synthesized in the brain (35), the high choline BUI values are attributable to postnatal synapse formation and myelination. Neonatal BBB transport mechanisms are therefore adapted to ensure an adequate supply of neurotransmitter precursors such as tryptophan and choline. These data also suggest an alteration in the turnover rate or biologic half-life for tryptophan and choline in the adult, as compared to neonatal brain.

The higher influxes of amino acids, observed in studies of suckling as compared to young adult rats, have been interpreted as providing substrate for rapid cerebral protein formation during this time of rapid brain growth (1). [It is generally believed that adequate amounts of all appropriate amino acids in the diet are necessary to ensure protein synthesis, but the brain is unusual in that certain amino acids may be synthesized from glucose (17). We have not yet measured neonatal brain uptake of even a representative number of essential amino acids.] The increase in arginine uptake which we observed might be attributable to an increase in histone synthesis in the developing rabbit. High concentrations of basic amino acids (particularly arginine and lysine) are present in human breast milk, and even higher concentrations have been recorded in colostrum than in mature milk (15). Dietary levels of substrate directly influence brain levels $(16,27,29)$. It has also been demonstrated that choline levels are five times greater in the plasma of newborn infants $(50 \mu \mathrm{M})$ than in adults (37). Thus, the alterations seen in the BBB transport mechanisms of the neonates might be related to substrate concentrations in plasma and break milk, and possess affinities and transport rates which facilitate optimal brain development.

The elevated uptake rates seen for certain substrates in the neonatal period relative to the adult suggest that the developing brain has a substantially increased requirement for some of these compounds. The metabolites examined in the present study are precursors of substrate-limited pathways, thus the dietary absence of adenine or choline could, for example, result in decreased brain synthesis of end products such as nucleic acids or lecithins. Furthermore, adenine and choline are not routinely included in clinical hyperalimentation. The present studies therefore call for reconsideration of the practice of intravenous feeding of newborns with glucose saline. The apparent dietary requirements of developing brain (and possibly other tissues), together with a knowledge of the constituents of colostrum, breast milk and neonatal plasma levels, could be utilized in the rational development of a more appropriate intravenous formulation. If the newborn BBB in some way reflects the needs of the unborn fetal $\mathrm{BBB}$, then this supplemental feeding might be even more appropriate in situations where the infant is premature, or of low body weight for gestational age. Empirical testing of this simple concept would not be expensive, and there may be some potential for a significant improvement in neonatal care.

\section{REFERENCES AND NOTES}

1. Banos, G., Daniel, P. M., and Pratt, O. E.: The effect of age upon the entry of some amino acids into the brain, and their incorporation into cerbral protein. Develop. Med. Child Neurol., 20: 335 (1978).

2. Bolwig, T. G., Hertz, M., and Holm-Jensen, J.: Blood brain barrier permeability during electroshock seizures in the rat. Eur. J. Clin. Invest., 122: 249 (1977).

3. Bolwig, T. G., Hertz, M. M., Paulsen, O. B., Spotoft, H., and Rafealsen, O. J.: The permeability of the blood brain barrier during electrically induced seizures in man. Eur. J. Clin. Invest., 7: 87 (1977).

4. Braun, L. D., Cornford, E. M., and Oldendorf, W. H.: Newborn blood-brain barrier is selectively permeable and differs substantially from the adult. J. Neurochem., 34: 147 (1980).

5. Caley, D. W., and Maxwell, D. S.: Development of the blood vessels and extracellular spaces during postnatal maturation of rat cerebral cortex. $\mathbf{J}$. Comp. Neurol., 138: 31 (1970).

6. Cornford, E. M. and Oldendorf, W. H.: Independent blood brain barrier transport systems for nucleic acid precursors. Biochim. Biophys. Acta, 394: 211 (1975).

7. Cornford, E. M. and Oldendorf, W. H.: Blood brain barrier permeability to amines and amine precursors. In: Noncatecholic Phenylethylamines, A. D. Mosnaim and M. E. Wolf, Eds. pp. 21-51 (Marcel Dekker, New York, NY 1980).

8. Cornford, E. M., Braun, L. D., and Oldendorf, W. H.: Carrier mediated blood brain barrier transport of choline and certain choline analogs. J. Neurochem, 30: 299 (1978).

9. Cornford, E. M., Braun, L. D., Crane, P. D., and Oldendorf, W. H.: Blood brain barrier restriction of peptides and the low uptake of enkephalins. Endocrinology, 103: 1297 (1978).

10. Cremer, J. E., Braun, L. D., and Oldendorf, W. H.: Changes during development in transport processes of the blood brain barrier. Biochim. Biophys. Acta, 448: $633(1976)$

11. Dahlquist, G. and Persson, B.: The rate of cerebral utilization of glucose, ketone bodies, and oxygen: a comparative in vivo study of infant and adult rats. Pediatr. Res., 10:910 (1976).

12. Daniel, P. M., Love, E. R., and Pratt, O. E.: The effect of age upon the influx of glucose into brain. J. Physiol., 274: 141 (1978).

13. Diamond I. and Schmid, R.: Experimental bilirubin encephalopathy. The mode of entry of bilirubin 14-C into the central nervous system. J. Clin. Invest., 45: 678 (1966)

14. Diamond, I.: Bilirubin binding and kernicterus. Adv. Pediatr., 16: 99 (1969).

15. Diem, K. Ed. Documenta Geigy Scientific Tables 6th ed., pp. 514-515 (Geigy, Ardsley, New York, NY 1962).

16. Fernstrom, J. D. and Faller, D. V.: Neutral amino acids in the brain: developmental and dietary modulations. J. Neurochem., 30: 1531 (1978).

17. Hawkins, R. A., Miller, A. L., Cremer, J. E., and Veech, R. L.: Measurement of glucose utilization in rat brain in vivo. J. Neurochem., 23: 917 (1974).

18. Jope, R. F. and Jenden, D. J.: Choline and phospholipid metabolism and the synthesis of acetylcholine in rat brain. J. Neurosci. Res., 4: 69 (1979).

19. Maisels, M. J.: Bilirubin: on understanding and influencing its metabolism in the newborn infant. Pediat. Clin. N. Amer., 19: 447 (1972).

20. Mietus, L. J. and Pardridge, W. M.: Kinetic constants of blood brain barrier neutral amino acid transport: comparison of newborn rabbit and adult rat. Soc. Neuroscience (Abstract), 7: (1981).

21. Moore, T. J., Lione, A. P., Sugden, M. C., and Regen, D. M.: Beta-hydroxybutyrate transport in the rat brain: developmental and dietary modulations. Am. J. Physiol., 230: 619 (1976).

22. Oldendorf, W. H.: Measurement of brain uptake of radiolabeled substances using a tritiated water internal standard. Brain Res., 24: 372 (1970).

23. Oldendorf, W. H.: Lipid solubility and drug penetration of the blood brain barrier. Proc. Soc. Exp. Biol. Med., 147: 813 (1974).

24. Oldendorf, W. H., Hyman, S., Braun, L., and Oldendorf, S. Z.: Blood brain barrier penetration of morphine, codeine, heroin and methadone after carotid injection. Science, 178: 984 (1972).

25. Oldendorf, W. H. and Szabo, J.: Amino acid assignment to one of three bloodbrain barrier amino acid carriers. Am. J. Physiol, 230: 94 (1976).

26. Oldendorf, W. H. and Braun, L. D.: [3-H] tryptamine and [3-H] water as diffusible internal standards for measuring brain extraction of radiolabeled substances following intracarotid injection. Brain Res., 113: 219 (1976).

27. Pardridge, W. M.: Regulation of amino acid availability to the brain. In: Nutrition and the Brain, R. J. Wurtman and J. J. Wurtman Eds. Vol. 1: pp. 141-204 (Raven, New York, NY 1977)

28. Pardridge, W. M.: Tryptophan transport through the blood brain barrier: in vivo measurement of free and albumin bound amino acid. Life Sci., 25: 1519 (1979).

29. Pardridge, W. M. and Oldendorf, W. H.: Transport of metabolic substrates through the blood-brain barrier. J. Neurochem., 28: 5 (1977).

30. Pardridge, W. M. and Mietus, L. J.: Transport of thyroid and steroid hormones through the blood brain barrier of the newborn rabbit: a primary role for protein bound hormone. Endocrinology, 107: 1705 (1979).

31. Purdy, J. L. and Bondy, S. C.: Blood-brain barrier: selective changes during maturation. Neuroscience, 1: 125 (1976).

32. Raichle, M. E., Eichling, J. O., Straatman, M. G., Welch, M. J., Larson, K. B., and Ter-Pogossian, N. M.: Blood brain barrier permeability to 11-C labeled alcohols and 15-O labeled water. Am. J. Physiol., 230: 543 (1976).

33. Saunders, N. R.: Ontogeny of the blood brain barrier. Exp. Eye Res. Suppl., 523 (1977).

34. Sershen, H. and Lajtha, A.: Capillary transport of amino acids in the developing brain. Exp. Neurol., 53: 465 (1976). 
35. Sparf, B.: On the turnover of acetylcholine in the brain. Acta Physiol. Scand. (Suppl.), 397: 1 (1973).

36. Yuwiler, A., Oldendorf, W. H., Geller, E., and Braun, L. D.: The effect of albumin binding and amino acid competition on tryptophan uptake into brain. J. Neurochem., 28: 1015 (1977).

37. Zeisel, S. H., Epstein, M. F., and Wurtman, R. J.: Elevated choline concentration in neonatal plasma. Life Sci., 26: 1827 (1980).

38. The authors thank Dr. William M. Pardridge, Dr. David M. Treiman and Dr Antonio V. Escueta for their assistance.
39. Requests for reprints should be addressed to: Dr. Eain M. Cornford, Southwestern Regional V.A. Epilepsy Center, Veterans Administration Medical Center, 691 127 Wadsworth, Los Angeles, CA 90073.

40. This research was supported by federal funds from the Department of Health, Education and Welfare under contract number NO1-NS-0-2332 and supported by the Veterans Administration.

41. Received for publication June 1, 1981.

42. Accepted for publication August 20, 1981. 